\title{
Você está entendendo? Contribuições dos estudos de fala-em-interação para a prática do teleatendimento
}

\author{
Cristiane Maria Schnack \\ Doutora em Linguística Aplicada e Professora na UNISINOS,crischnack@yahoo.com.br \\ Daiane Baldasso Bohm \\ Mestranda em Linguística Aplicada na UNISINOS, daianebaldasso@hotmail.com
}

\section{Resenha do livro:}

OSTERMANN, A.C.; OLIVEIRA, M. do C. (Orgs.) Você está entendendo? Contribuições dos estudos de fala-em-interação para a prática do teleatendimento. Campinas: Mercado de Letras, 2015. 116p.

${ }^{1}$ REDDY, M. (1979[2000]. A metáfora do conduto: um caso de conflito de enquadramento na nossa linguagem sobre a linguagem. Cadernos de Tradução, n 9, Porto Alegre, pp.5-47, jan/ mar. Tradução de Ilesca Holsbach, Fabiano Gonçalves, Marcela Migliavacca e Pedro Garcez.
O teleatendimento para fins institucionais é, muitas vezes, motivo de indignação de quem o utiliza, especialmente devido à má qualidade do serviço prestado. A principal causa desta má qualidade é "o modelo de comunicação que orienta a prática desses atendimentos" (OSTERMANN, OLIVEIRA e SOUZA, 2015, p. 11). Segundo as autoras, esse modelo pode ser entendido como a "metáfora do conduto" (Reddy, 2000) ${ }^{1}$, como se as palavras tivessem significados fixos, independente do contexto, e fossem transmitidas de forma intacta ao interlocutor. O resgate da humanização no teleatendimento implica, entre outros fatores, na busca pelo entendimento que as pessoas que utilizam o serviço constroem a respeito do que está sendo negociado, ou seja, no abandono do modelo de comunicação vigente na maior parte das empresas e instituições que prestam este tipo de serviço. Humanizar o teleatendimento, ao mesmo tempo, torna-se uma necessidade à medida que a procura por estes serviços se dá por pessoas que buscam a resolução de problemas ou ajuda em geral. Isso significa que o teleatendimento não deveria se configurar em mais um problema a ser enfrentado pelas pessoas que o procuram.

É nesse cenário que se insere o livro intitulado Você está entendendo?: Contribuições dos estudos de fala-em-interação 
para a prática do teleatendimento, organizado por Ostermann e Oliveira, pautado pela perspectiva teórico-metodológica da Análise da Conversa, que objetiva analisar as interações entre teleatendentes de serviços prestados na saúde, segurança e fornecimento de energia e o público, e as ações provenientes dessas interações, a fim de auxiliar e contribuir com o processo de humanização desses atendimentos, conscientizando os profissionais sobre essa necessidade, e assim aprimorar o serviço oferecido. A obra está organizada em seis capítulos, sendo que, no primeiro, além de apresentarem a importância social deste estudo, as autoras detalham a forma com que os dados utilizados foram coletados e transcritos, além de fazerem um detalhamento dos demais cinco capítulos do livro.

O segundo capítulo, intitulado O controle do Incontrolável: Scripts para Interações Irreais, de autoria de Ostermann e Souza, o script institucional é tratado como um dos responsáveis pelo abandono da interação e da "necessidade de se repensar alguns conceitos, já que elas (as práticas realizadas pelos teleatendentes) traduzem um uso adequado e um uso inadequado (dos scripts)" (p. 27). O script é um roteiro de perguntas de sondagem e confirmação para captar a necessidade do cidadão. Entretanto, como bem demonstrado pelas autoras nas análises apresentadas, por vezes, esta sequência faz-se desnecessária e inapropriada para a necessidade da usuária do serviço de teleatendimento em questão. Isto ocorre porque o "entendimento mútuo é construído a cada contribuição dos falantes" (p. 28) e é imprescindível para a interação.

Deparamo-nos com o confronto entre a burocracia estabelecida pela instituição e controlada pelos supervisores e monitores, e a necessidade de os atendentes lidarem com o mesmo script de formas diferenciadas. Segundo Hepburn e Potter (2007) $)^{2}$, um ponto muito importante na interação institucional é o acolhimento a pessoas em situações supostamente delicadas ou de vulnerabilidade. Muitos atendentes o fazem considerando as reais necessidades dos usuários, priorizando, assim, a humanização do serviço. Já

${ }^{H}$ EPBURN, A. e POTTER, J. (2007). Crying receipts: time, empathy, and institutional practice. Research on Language and Social Interaction, vol. 40, n 1, pp. 89-116. em outras situações, prevalece o script, que por muitas vezes caracteriza a tentativa de controlar a interação, que é, no entanto, incontrolável por natureza.

No capítulo 3, Pereira e Ostermann atribuem duas causas ao atendimento deficitário dos assim chamados 
call centers: a dificuldade do atendente em "(1) traduzir um texto excessivamente técnico em outro compreensível a um usuário leigo, e (2) ajustar o que foi lido a um contexto de fala com o usuário" (p. 49). Diante dessa situação, os autores destacam a necessidade de recontextualização, já que o serviço visa "democratizar a informação de saúde e informar para a cidadania". Uma vez que os atendentes têm acesso a um banco de dados que contêm textos específicos na área da saúde, e a linguagem destes textos não é adequada ao público, a compreensão do interlocutor não acontece. Sendo assim, "produzir o texto do banco de dados como um texto de divulgação científica pode melhorar a qualidade do atendimento, favorecendo o atingimento da meta proposta para o serviço" (p. 65). Além disso, a verificação de dúvidas recorrentes dos usuários é sugerida a fim de inseri-las no banco de dados, a remodelação dos textos considerando o públicoalvo, e a capacitação dos atendentes para esta visão com foco na gestão de pessoas.

Del Corona aborda, no capítulo 4, outro cenário relacionado ao teleatendimento, vinculado à segurança, e que se conhece como "o serviço 190" da Brigada Militar. Dada a relevância social do serviço prestado, a qualidade e a prontidão do atendimento são fundamentais para a execução do envio da viatura ao local em que houve algum tipo de irregularidade que possa interferir na ordem social, podendo ser fundamental em casos de vida ou morte. Assim como no Disque Saúde, o call center da Brigada Militar também dispõe de um procedimento padrão, através do preenchimento de um formulário disponível em um software de registro de ocorrência. Segundo a autora, a atenção excessiva ao preenchimento do formulário acaba por prejudicar a interação.

Há muitas informações a serem preenchidas e não há nenhum tipo de particularização que respeite cada caso em questão em sua especificidade. Há um script a ser seguido envolvendo o teleatendente, o usuário e o software do formulário. Cabe ressaltar também que os usuários do "serviço 190" buscam uma solução para determinado caso, que, segundo a autora, tende a ser imediato. Entretanto, o entendimento entre os participantes (p. 77) em relação ao local da ocorrência é imprescindível para o serviço de envio da viatura acontecer de forma bem-sucedida. Há, em 
muitas situações, falta de informação ou fornecimento de informações errôneas e confusas, o que acaba por tornar a ligação do usuário descartável. A autora registra que "pode ser mais útil à população se forem desenvolvidas maneiras mais dinâmicas de obtenção de referência de um lugar" (p. 89) e também recomenda o investimento do governo em campanhas que letrem a população ao funcionamento do serviço de “Atendimento Telefônico 190", a fim de facilitar o processo e aperfeiçoar a prática.

Por fim, no capítulo 5, Borges, Ostermann e Oliveira tratam sobre os Apagões Interacionais em Episódios de Tomada de Decisão em momentos cruciais em contexto de fornecimento de eletricidade. Ao analisar uma interação entre profissionais do Centro de Operação do Sistema da Subestação Acaraí, as autoras enfatizam "o papel da orientação dos participantes no processo de construção de uma compreensão mútua voltada para a tomada de decisão durante eventos inesperados" (p. 95). Ou seja, é preciso que haja essa compreensão mútua para que decisões sejam tomadas de forma assertiva, efetiva e em tempo hábil. A agilidade exigida em determinadas situações pode ser prejudicada frente à falta de entendimento dos interagentes e o desalinhamento dos mesmos.

Mais uma vez, a padronização dos processos, os scripts, vem de encontro às práticas profissionais particularizadas que exigem decisões instantâneas que levem em consideração as especificidades da situação vivenciada, já que são de grande importância para cada situação. As autoras e organizadoras da obra, Oliveira e Ostermann, voltam-se para as "lições da caixa-preta", que são aquelas que não se tem conhecimento por acesso direto, ressaltando a importância de "ter competência interacional para exercer atividades centradas na fala" (p. 113).

Ao fim e ao cabo, no livro fica registrada a sugestão de programas de formação na área de interação e comunicação a fim de possibilitar a particularização dos atendimentos telefônicos dos mais variados fins e humanizar os atendimentos em busca de decisões acertadas e soluções imediatas. Você está entendendo? nos faz refletir sobre a importância das interações interpessoais para o alcance de resultados esperados, especialmente em contextos de teleatendimento, nos quais a pauta principal é a resolução de uma situação que se coloca problemática para usuários do serviço. Através da análise da sequencialidade das 
interações, é possível observar tensões entre as expectativas de usuários e a orientação dos profissionais, projetando assim espaços de formação para otimizar as práticas e obter sucesso na tomada de decisões das mais variadas ordens.

O livro é recomendado para pesquisadores/as e profissionais das áreas de linguagem, ciências sociais aplicadas, e das áreas diretamente vinculadas com os contextos sociais pesquisados, como a área da saúde, da segurança e da energia. Profissionais especialmente interessados/as e vinculados/as com a melhoria constante do serviço prestado podem encontrar no livro subsídios para incrementar programas de formação profissional continuada ou de formação universitária. Por fim, acadêmicos/as responsáveis pela proposição e estruturação de currículos universitários podem beneficiar-se da leitura como insumo para propor disciplinas que aliem conhecimento técnico específico e realização prática no serviço prestado.

Palavras-chaves: teleatendimento, humanização, fala-eminteração, scripts, Análise da Conversa. 